Research Article

\title{
Experimental Study on Bolt-Spliced Prefabricated Steel Frame Beams
}

\author{
Ran He ${ }^{D}$, Zaihua Zhang ${ }^{D}$, and Jingchao Li \\ College of Civil Engi neering, Hunan City University, Yiyang, Hunan 413000, China \\ Correspondence should be addressed to Ran He; heran01033101@163.com and Zaihua Zhang; zaihua_zhang@163.com
}

Received 23 January 2020; Revised 3 October 2020; Accepted 19 October 2020; Published 29 October 2020

Academic Editor: Michael Yam

Copyright (c) 2020 Ran He et al. This is an open access article distributed under the Creative Commons Attribution License, which permits unrestricted use, distribution, and reproduction in any medium, provided the original work is properly cited.

\begin{abstract}
The prefabricated steel structural residence is characterized by modularization and standardization, which meets the requirement of industrial development. The steel frame beam needs to be fabricated in segments and assembled in site due to the limitation of transportation. In practical engineering, the steel frame beams need to be spliced along the beam span. A robust connection between the two steel beam segments is necessary as it will influence the load bearing capacity, stiffness, and stability of the steel frame. In total, 12 specimens were tested to investigate the influence of spliced types, loading patterns, and bolt types on the performance of the steel frame. The observed failure modes, load versus displacement curves, and moment versus rotation angle curves are presented. The test results show that the strength and deformability of bolt-spliced connections are generally good and similar to those of the prototype beam.
\end{abstract}

\section{Introduction}

The prefabricated structure has been widely accepted due to its advantages of high efficiency, energy saving, environment friendly, and high quality. The steel structure is suitable for the prefabricated structure, which is characterized by lightweight, good seismic resistance, flexible layout, high construction efficiency, and being easy to assemble and recycle [1-5]. For steel structure, all the steel beams can be assembled with steel columns using bolts, which significantly simplify the construction process and improve the construction efficiency. However, the steel frame beams need to be prefabricated in segments due to the limitation of transportation conditions. As shown in Figure 1, the steel frame beams can be spliced at the midspan to reduce the splicing work in the field. However, it is important to adopt a robust splicing method to ensure the performance of the bolt-spliced steel frame beams.

To date, three main spliced methods of steel beams are proposed: bolt-spliced steel beam with flanges (FLB), boltspliced steel beam with extended end plates (EPB), and boltspliced steel beam with cover plates (CPB). Some preliminary studies have been conducted to investigate the performance of bolt-spliced steel beams. Kulak and Green [6] studied the mechanical performance of CPBs, in which only the web of the steel beam was spliced with cover plates. McMullin and Astaneh-Asl [7] investigated the seismic behavior of the column-tree moment-resisting frame and concluded that the splicing joint of the steel beam could provide stable energy dissipation. Al-Janabi [8] experimentally and theoretically investigated the influences of splice location, splice connection type, and the number of splices on the static and dynamic performance of CPBs. Li et al. [9] performed a cyclic test on three CPBs to investigate the frictional energy-dissipation mechanism. Sumner [10] conducted an experimental study on the performance of EPBs, and design procedures were proposed. Dessouki et al. [11] investigated the influence of beam depth, end plate thickness, bolts, and end plate stiffener on the performance of EPBs using a finite element model. Kawecki and Kozlowski [12] conducted an experimental program on large-scale EPBs. Tong et al. [13] conducted experimental and theoretical studies on the bending behavior of CPBs, in which the influence of bolt number was investigated. It was 


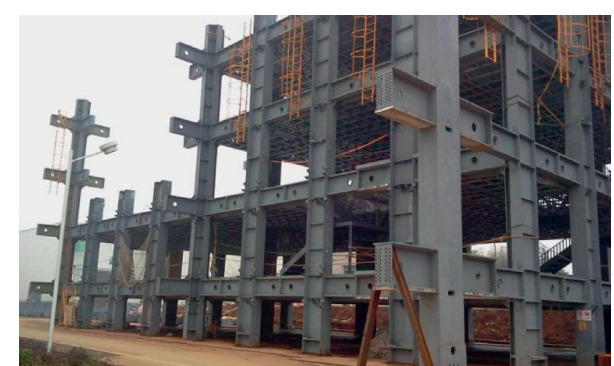

Figure 1: Splicing joint of steel frame beam in practical engineering.

found that the slip of bolt had an adverse effect on the flexural stiffness of the steel beams, which also led to the dissatisfaction of the plane assumption.

Previous studies have demonstrated the feasibility of the bolt-spliced steel frame beam. However, studies on the performance of bolt-spliced steel beam at the midspan are still limited and comparisons among the FLB, EPB, and CPB specimens cannot be found in the previous studies. Therefore, 12 specimens were prepared and tested in this study. The obtained failure modes, load versus displacement curves, and moment versus rotation angle curves were analyzed and discussed in detail.

\section{Experimental Program}

2.1. Specimens. In total, 12 specimens were prepared and tested to failure, including 5-bolt-spliced steel beam with flanges (FLB), 3-bolt-spliced steel beam with extended end plates (EPB), 3-bolt-spliced steel beam with cover plates $(\mathrm{CPB})$, and 1 prototype beam (PB). The investigated parameters include the spliced types (flange, cover plate, or extended end plate), loading patterns (pure bending or midspan load), and bolt types (normal-strength bolts, normal-strength bolts with spring washer, or high-strength bolts). Specimen details are listed in Table 1, in which the dimension is presented in the way of height $\times$ width $\times$ web thickness $\times$ flange thickness of the steel beam, $L$ is the whole beam length, $l$ is the length of the tested beam segment, and filled plate means that additional $4 \mathrm{~mm}$ thick steel plates are inserted between the flanges of steel beam segments. The specimen designation begins with the type of specimens $(\mathrm{PB}$, $\mathrm{FLB}, \mathrm{EPB}$, or $\mathrm{CPB}$ ), followed by the loading patterns (1 and 2 mean, resp., midspan loading and pure bending loading) and specimen characteristics, that is, $S 1$ and $S 2$, are adopted to distinguished the FBL-1 specimens with the same parameters, $F 0, F 1$, and $F 2$ denote, respectively, FLB-2 specimens with 0,1 , and 2 filled plates, and $\mathrm{N}, \mathrm{SW}$, and $\mathrm{H}$ represent EPB-1 or CPB-1 specimens using normal-strength bolts, normal-strength bolts with spring washer, or highstrength bolts, respectively. It should be noted that the strength grade of the steel plate used in this paper is Q345. Tensile coupons were prepared and tested to determine the mechanical properties of the steel beam and cover plate [14], as listed in Table 2. The yield strength and tensile strength of the bolts used in this study were, respectively, $900 \mathrm{MPa}$ and $1000 \mathrm{MPa}$, which were provided by the manufacturer.

Dimensions and details of specimens are illustrated in Figures 2 and 3, respectively. In total, there were three steps for the fabrication of the specimens: (1) The steel plates for the specimens were cut and punched according to the dimensions shown in Figures 2 and 3. (2) The steel plates for the steel beam were welded together and end plates were welded to the steel beams for FLB and EPB specimens. (3) Assemble the whole steel beams and fasten the bolts.

2.2. Instrument and Measuring Scheme. All the specimens were tested using the test setup shown in Figure 4, including a midspan loading scheme and a pure bending loading scheme. The pure bending moment is applied with the assistance of a distribution beam. The vertical load applied to the specimens consists of two stages, namely, load-control stage and displacement-control stage, respectively. The load was applied with an increment of $20 \mathrm{kN}$ in the load-control stage, while an increment of approximately $2.5 \mathrm{~mm}$ was adopted once beyond the yield load of specimens.

As shown in Figure 5, six displacement transducers were employed to monitor the displacement of specimens. 1\#-3\# displacement transducers were used to record the vertical deformation of the quartered sections for steel beams. For FLB specimens under pure bending, additional three displacement transducers were arranged near the flanges. 4\# displacement transducer was used to measure the opening displacement of flanges, while $5 \#$ and $6 \#$ displacement transducers were, respectively, used to monitor the transverse displacements of the bottom and top sides of beam flanges.

\section{Experimental Results}

3.1. Failure Modes. Typical failure modes of FLB specimens under pure bending are shown in Figure 6. All the specimens experience a smooth increase in deformation. In the initial stage, the displacement increases nearly linearly with the increasing load, followed by a quicker increase of displacement with increasing plastic deformation. Then, the displacement increases significantly beyond the yield load of the specimens. The bottom end of the flanges is found to be opened in all specimens due to the bending moment. However, no visible opening of flanges is observed within the region fastened with bolts.

Figure 7 shows the typical failure modes of specimens subjected to midspan load. For FLB specimens (Figure 7(a)), the failure mode is similar to that of FLB specimens under pure bending. As shown in Figure 7(b), for CPB specimens, the top flanges of the steel beam segments get very closed, while the distance between the bottom flanges increases significantly. In addition, no obvious opening is found in EPB specimens. Not that initial deficiency is found in 
TABle 1: Specimen details.

\begin{tabular}{lcccccc}
\hline Specimens & Dimension $(\mathrm{mm})$ & $L(\mathrm{~mm})$ & $l(\mathrm{~mm})$ & Spliced type & Filled plate & Loading pattern \\
\hline PB-2 & $267 \times 100 \times 8 \times 8$ & 4000 & 3000 & - & - & - \\
FLB-1-S1 & $267 \times 100 \times 8 \times 8$ & 4000 & 3000 & Flange & Pure bending \\
FLB-1-S2 & $267 \times 100 \times 8 \times 8$ & 4000 & 3000 & Midspan & Midspan \\
FLB-2-F0 & $267 \times 100 \times 8 \times 8$ & 4000 & 3000 & Flange & Flange & $1 \times 4 \mathrm{~mm}$ \\
FLB-2-F1 & $267 \times 100 \times 8 \times 8$ & 4000 & 3000 & Flange & $2 \times 4 \mathrm{~mm}$ & Pure bending \\
FLB-2-F2 & $267 \times 100 \times 8 \times 8$ & 4000 & 3000 & Pure bending \\
EPB-1-N & $267 \times 100 \times 8 \times 8$ & 4000 & 3000 & Extended end plate & - & Midspan \\
EPB-1-SW & $267 \times 100 \times 8 \times 8$ & 4000 & 3000 & Extended end plate & Midspan \\
EPB-1-H & $267 \times 100 \times 8 \times 8$ & 4000 & 3000 & Extended end plate & - & Midspan \\
CPB-1-N & $267 \times 100 \times 8 \times 8$ & 4000 & 3000 & Cover plate & Midspan \\
CPB-1-SW & $267 \times 100 \times 8 \times 8$ & 4000 & 3000 & Cover plate & Midspan \\
CPB-1-H & $267 \times 100 \times 8 \times 8$ & 4000 & 3000 & Cover plate & - & Midspan \\
\hline
\end{tabular}

TABLE 2: Material properties of steel beam and cover plate.

\begin{tabular}{lccc}
\hline Material & Yield strength $(\mathrm{MPa})$ & Ultimate strength $(\mathrm{MPa})$ & Elastic modulus $(\mathrm{GPa})$ \\
\hline Steel beam $(8 \mathrm{~mm})$ & 381 & 512 & 189 \\
Cover plate $(6 \mathrm{~mm})$ & 394 & 536 & 193 \\
\hline
\end{tabular}

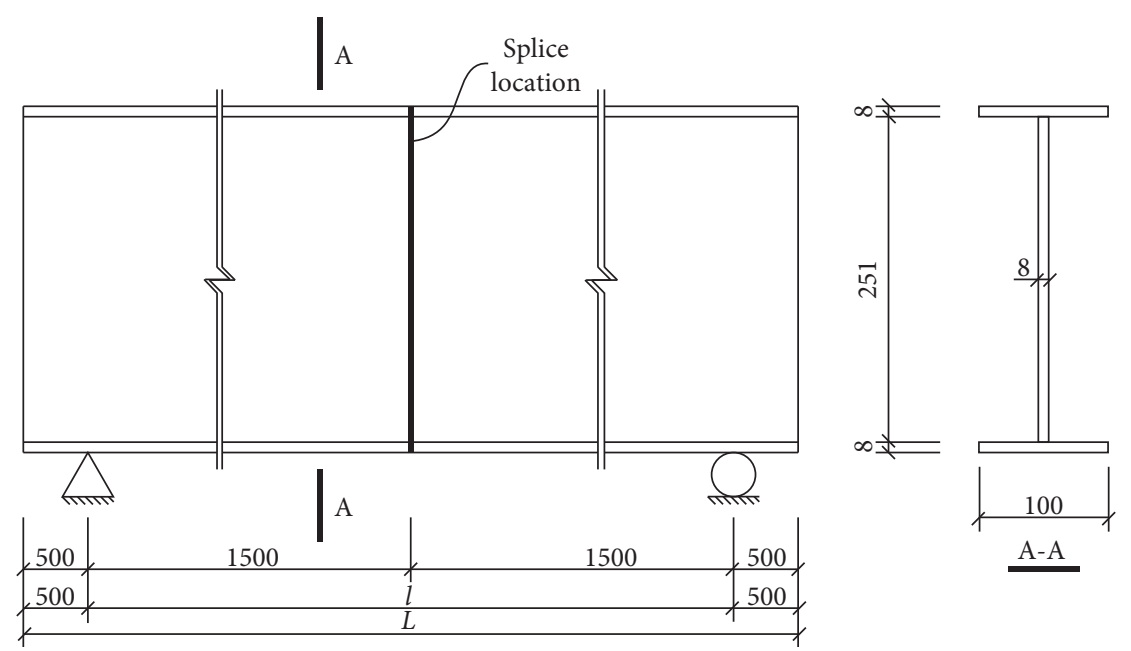

FIgURE 2: Dimension of specimens.

specimen EPB-1-H as the weld between the end plate and bottom flange fractures in the later loading process.

Typical vertical deformed shapes along the length of specimens are shown in Figure 8, in which the three obtained values are recorded by $1 \#-3 \#$ displacement transducers. As shown in Figure 8(a) and 8(b), the increase in the deformation at the initial stage is relatively uniform for specimens under pure bending. However, the vertical displacement increases quickly after $80 \%$ of the peak load $N_{p}$ and accelerates significantly near the peak load. The vertical deformed shapes of specimens under pure bending coincide better with the second-order parabolas. For specimens subjected to midspan load (Figures $8(\mathrm{c})-8(\mathrm{e})$ ), the deformation behaves more concentrated within the midspan region. The vertical deformed shapes for specimens under midspan load are in better agreement with the sinusoid curves.
3.2. Load versus Vertical Displacement Curves. Figure 9 shows the load $(N)$ versus vertical displacement $(\delta)$ curves of all the specimens, in which $D 1-D 3$ represent, respectively, the obtained displacement of $1 \#-3 \#$ displacement transducers. As shown in Figure 9, $\delta$ increases linearly with the increasing $N$ in the initial stage. Then, $N-\delta$ curves enter the elastic-plastic stage with the development of the plastic deformation, followed by the rapid increase of vertical displacement beyond the yield load of specimens. It could be observed in Figure 9 that $D 1$ is similar to $D 3$, which are both smaller than $D 2$. In addition, the difference between $D 2$ and $D 1 / D 3$ increases with the increase of $N$. As shown in Figures 9(e) and 9(f)), $N$ of FLB specimens with filled plate increases quickly with $\delta$ when $N$ exceeds approximately $250 \mathrm{kN}$, which may be caused by the deformation improvement induced by the filled plate. $N$ of specimen EPB-1$\mathrm{H}$ nearly levels off after the peak load (Figure 9(i)) due to the 


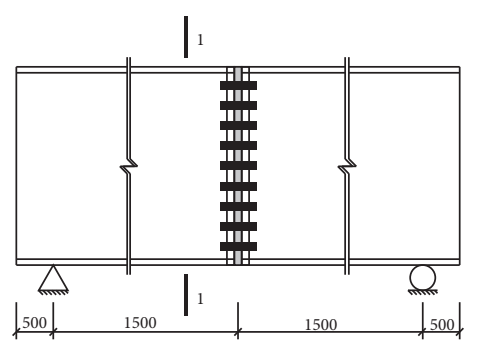

(a)
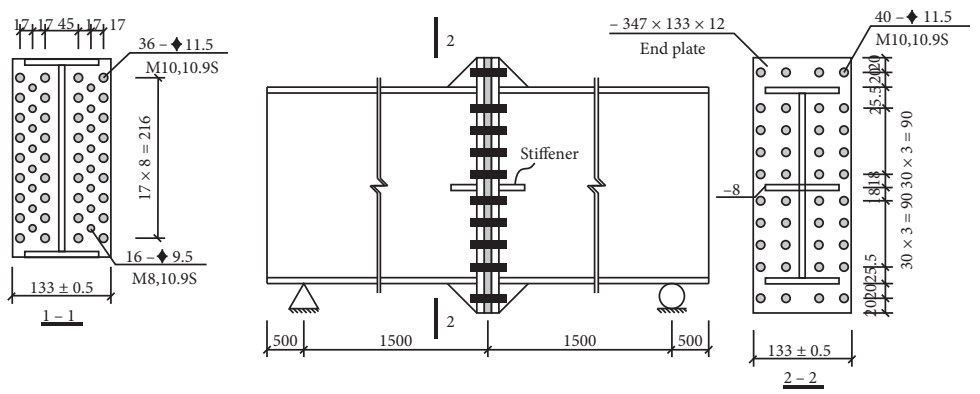

(b)

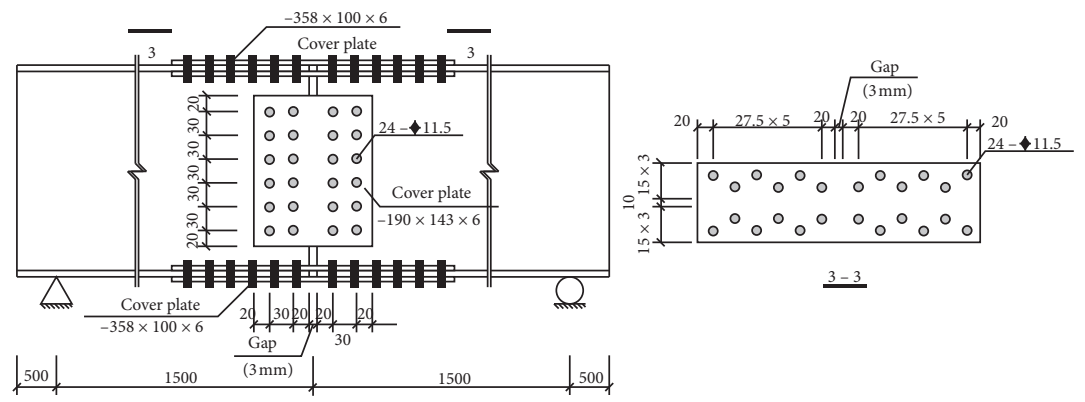

(c)

Figure 3: Details of specimens. (a) FLB specimens. (b) EPB specimens. (c) CPB specimens.
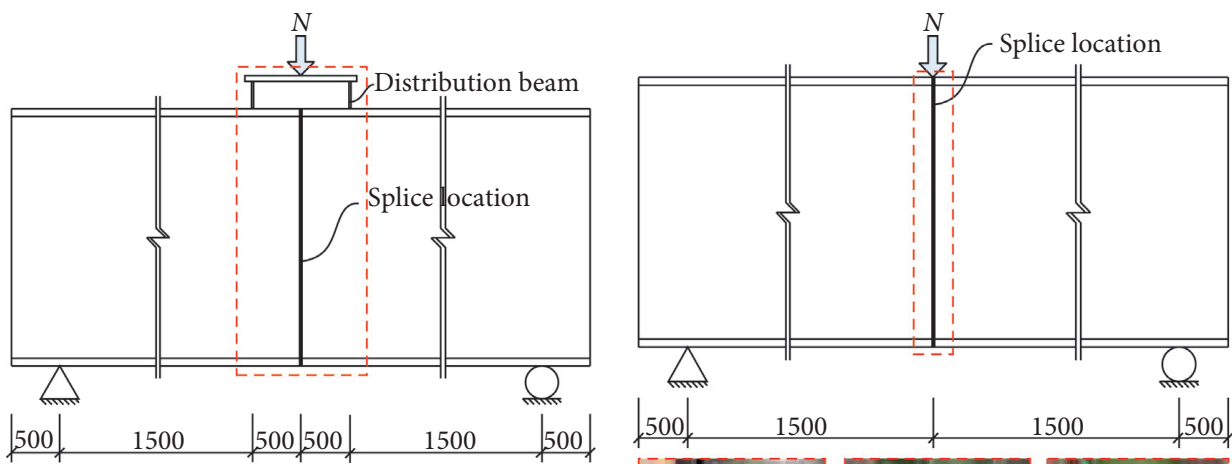

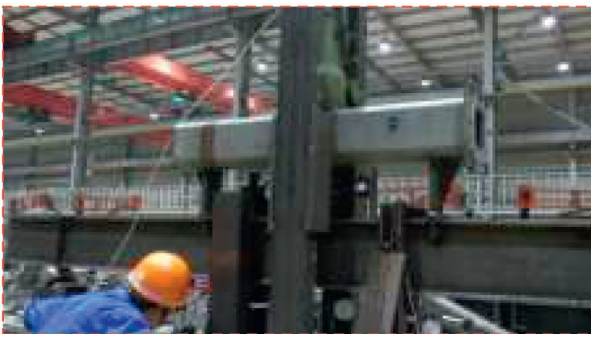

(a)
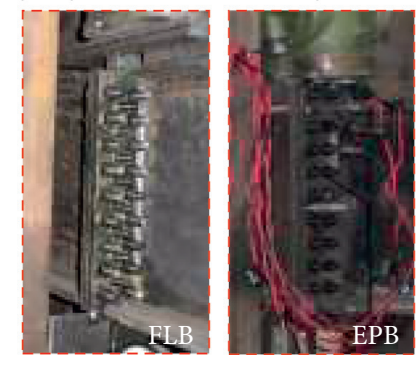

(b)

FIgure 4: Test setup. (a) Pure bending loading scheme. (b) Midspan loading scheme.

fracture of the weld between the bottom flange and end plate. For specimen CPB-1-SW (Figure 9(k)), sudden drops of load are observed during the loading process, which is caused by the sliding of spring washer. In addition, fluctuation of $N$ is observed for specimens FLB-1-S2 (Figure 9(c)) and CPB-1N (Figure 9(j)), which may be caused by the test errors.

Table 3 summarizes the key test results of the specimens, including the yield moment and corresponding midspan displacement $\left(M_{y}\right.$ and $\left.\Delta_{y}\right)$ and the peak moment and corresponding midspan displacement $\left(M_{P}\right.$ and $\left.\Delta_{P}\right)$. The yield load of specimens is determined by the geometric graphic method. As shown in Table 3, the deformability of the boltspliced steel beam is generally better than that of the prototype beam except for specimens FLB-2-F0, EPB-1-H, and CPB-1-H. In addition, the strength of FLB specimens under pure bending is close to that of the prototype beam. 


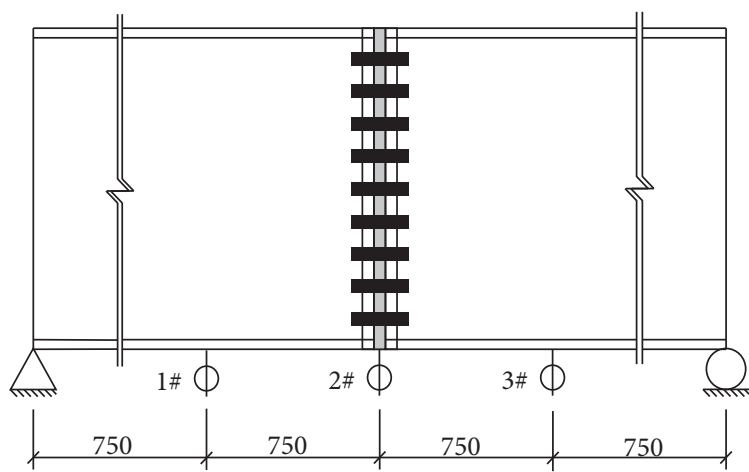

(a)

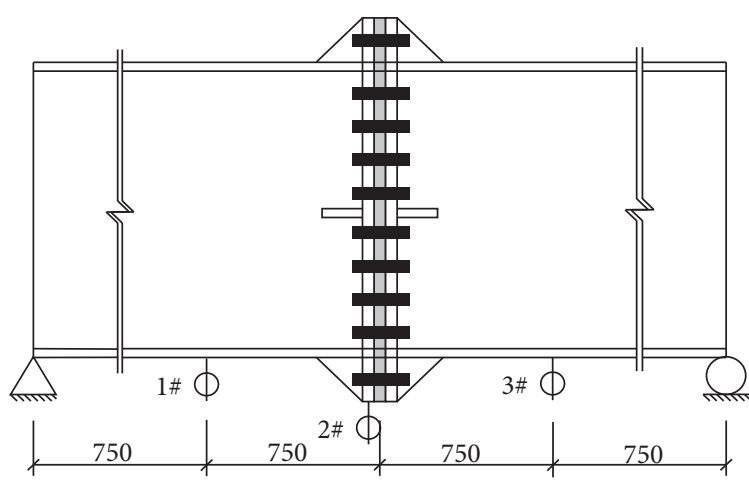

(c)

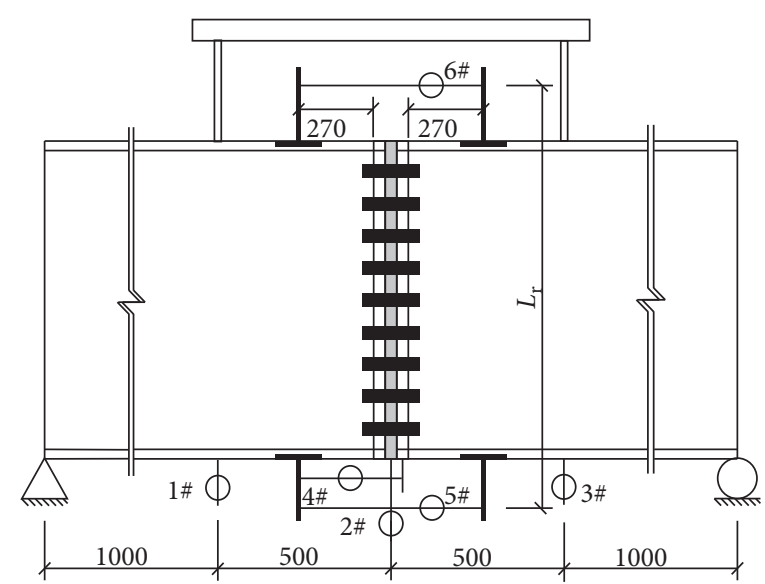

(b)

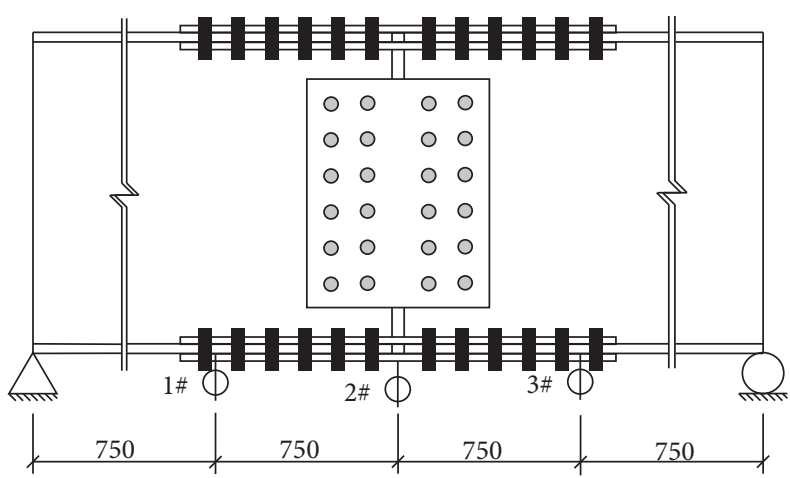

(d)

Figure 5: Layout of displacement transducers on the splicing joints of steel frame beams. (a) FLB specimens (midspan loading). (b) FLB specimens (pure bending). (c) EPB specimens. (d) CPB specimens.

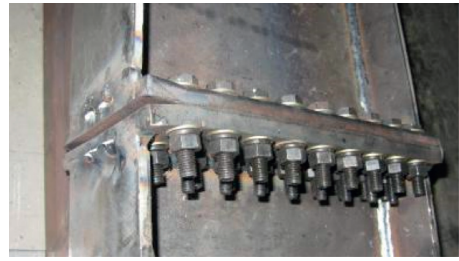

(a)

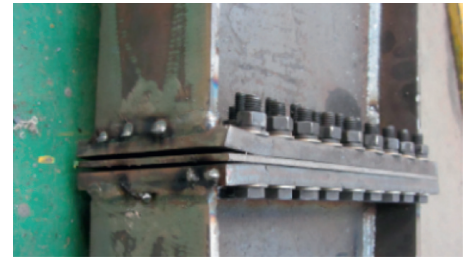

(b)

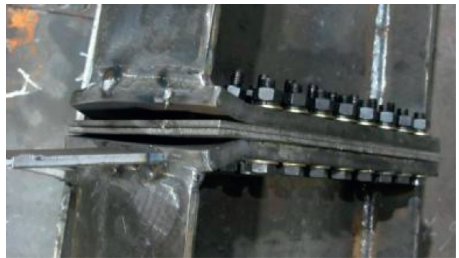

(c)

FIgURE 6: Typical failure mode of specimens under pure bending. (a) FLB-2-F0. (b) FLB-2-F1. (c) FLB-2-F2.

The influences of tested parameters on the $N-\delta$ curves of specimens are shown in Figure 10, in which the displacement is recorded by 2\# displacement transducer. For the specimens under pure bending (Figure 10(a)), the initial stiffness of specimen FLB-2-F0 is the largest as no filled plates are used. However, the use of filled plates will improve the deformability of specimens. The strength of FLB specimens is close to that of the prototype beam. For specimens subjected to midspan load (Figure 10(b)), the initial stiffness of the CPB specimens is larger than that of FLB and EPB specimens. In addition, the strength of $\mathrm{CPB}$ specimens is approximately equal to that of EPB specimens and both of them are larger than that of FLB specimens. As shown in Figure $10(\mathrm{c})$, the initial stiffness and strength of specimens
EPB-1-SW and EPB-1-H are larger than those of specimen EPB-1-N. Note that the initial deficiency of specimen EPB-1$\mathrm{H}$ is found as the weld between the end plate and bottom flange fractures during the loading process. For $\mathrm{CPB}$ specimens, a similar trend is found for specimens CPB-1-H and $\mathrm{CPB}-1-\mathrm{N}$ and the strength and deformability of specimen CPB-1-SW are the largest despite the two sudden load drops.

3.3. Moment versus Rotation Angle Curves. The rotation angle is calculated by equation (1), in which $D 5$ and $D 6$ are, respectively, the obtained displacement recorded by $5 \#$ and 6\# displacement transducers and $L_{r}$ is the distance between 


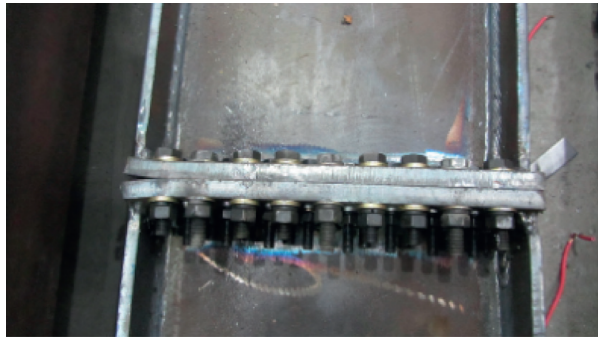

(a)

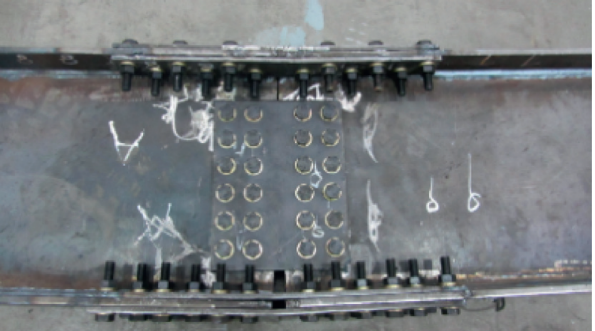

(b)

FIgURE 7: Typical failure mode of specimens under midspan load. (a) FLB-1-S2. (b) CPB-1-N.
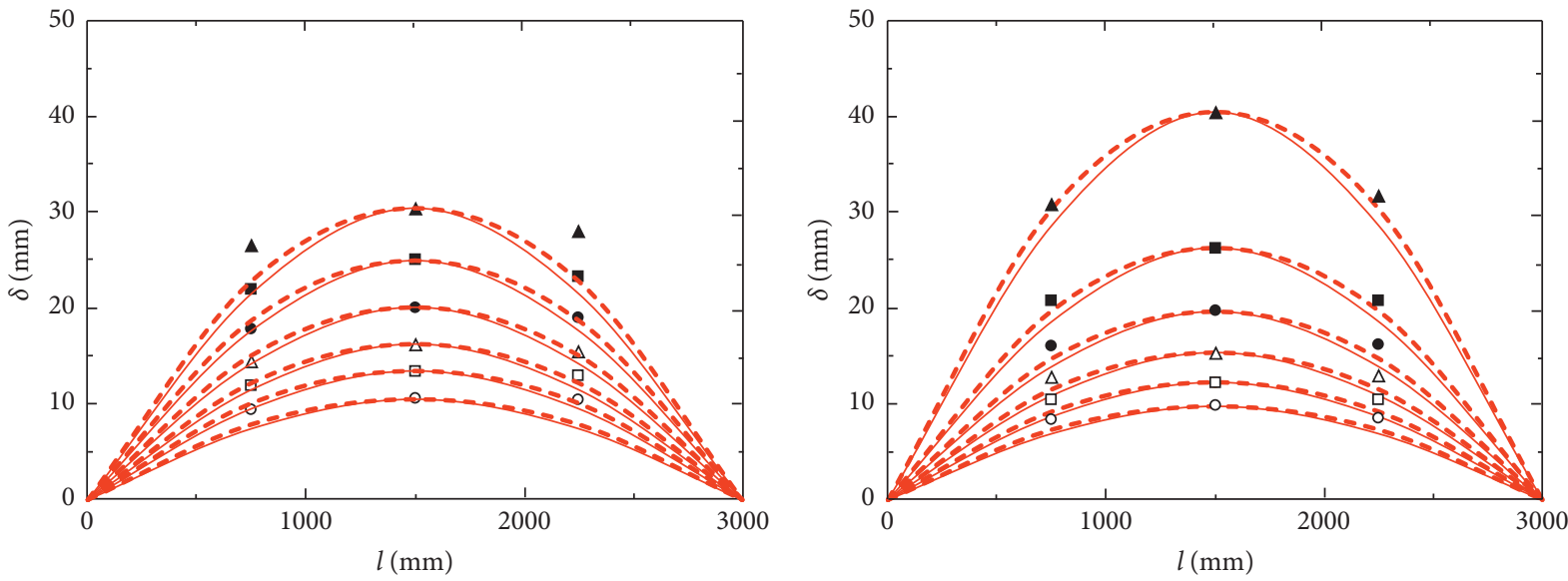

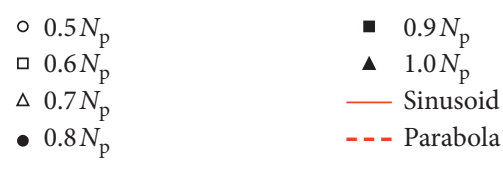

(a)

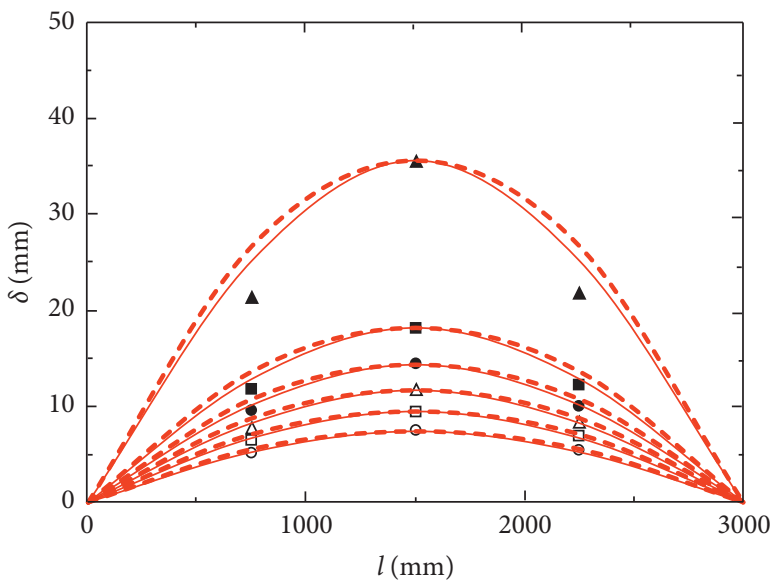

$\circ 0.5 N_{\mathrm{p}}$
$\square 0.6 N_{\mathrm{p}}$
$\triangle 0.7 N_{\mathrm{p}}$
$-0.8 N_{\mathrm{p}}$

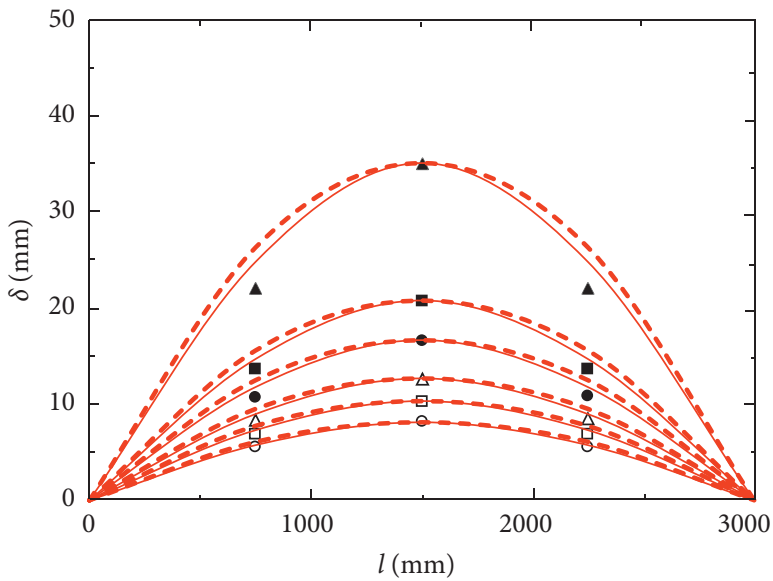

- $0.9 N_{\mathrm{p}}$

$\triangle 1.0 N_{\mathrm{p}}$

Sinusoid

- - Parabola

(b)

(c)

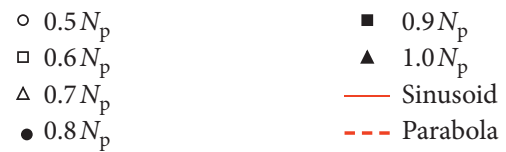

(d)

Figure 8: Continued. 


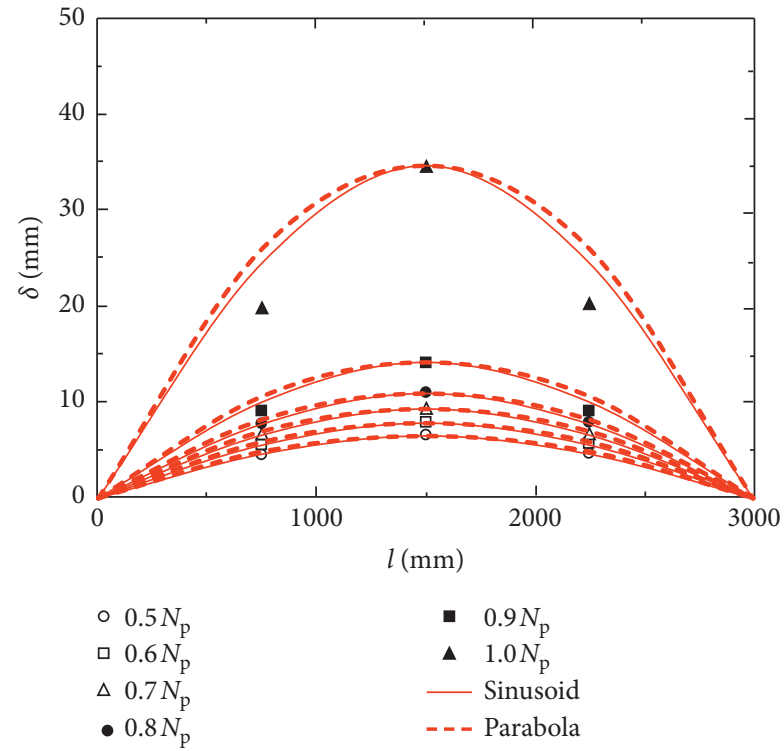

(e)

FIgURE 8: Typical vertical deformed shapes along the length of specimens. (a) PB-2. (b) FLB-2-F2. (c) FLB-1-S1. (d) EPB-1-N. (e) CPB-1-N.
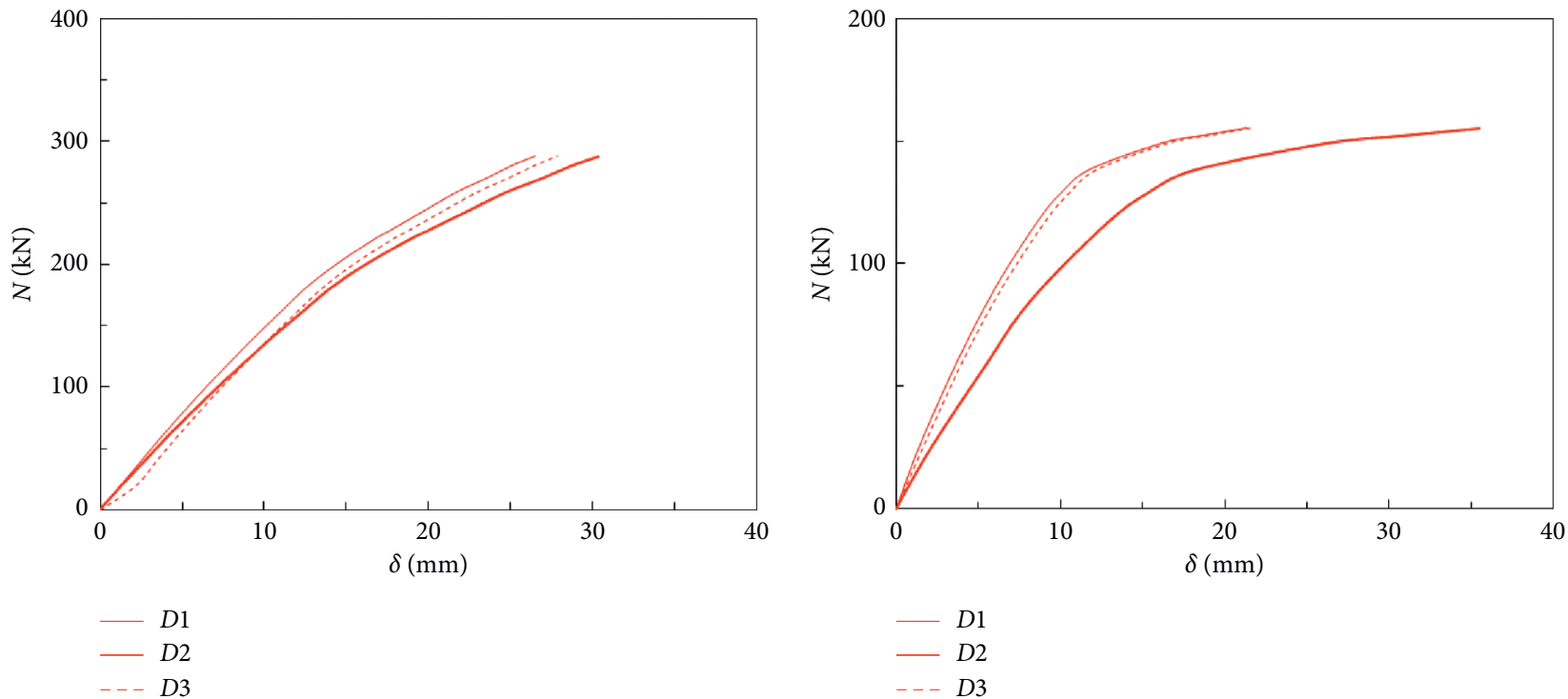

(a)

(b)

Figure 9: Continued. 

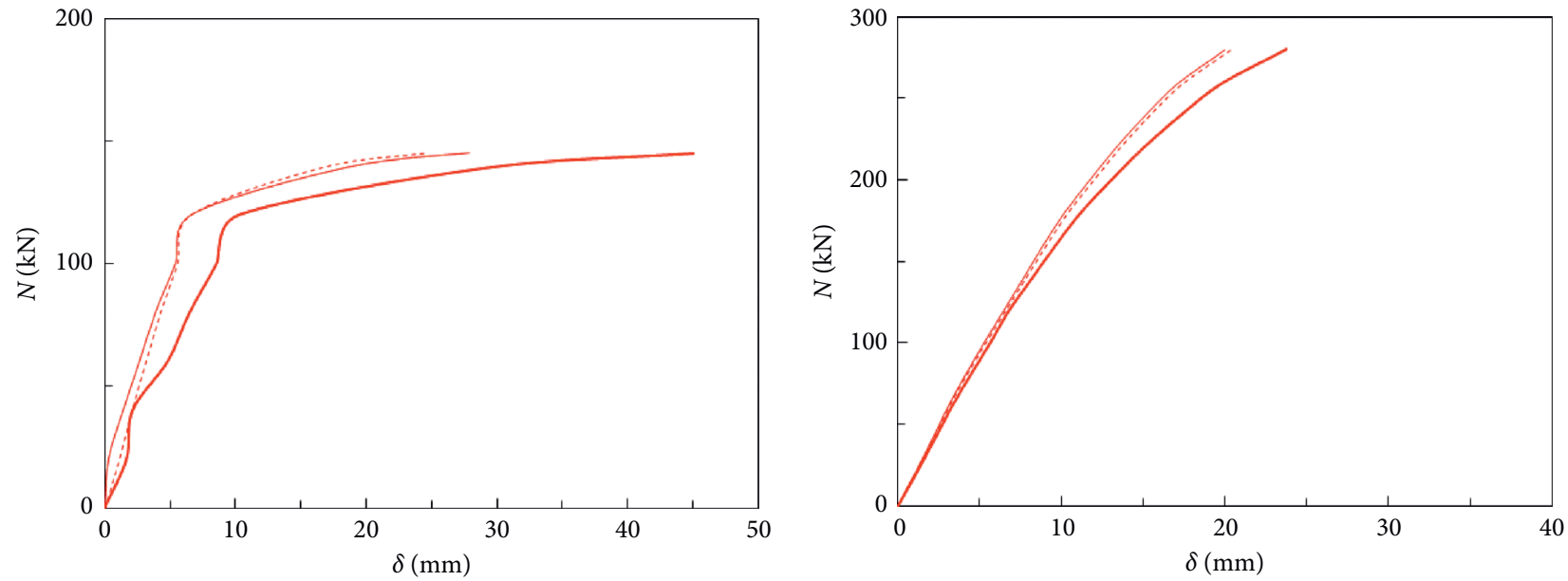

$-D 1$
$-D 2$
$---D 3$

$-D 1$

$-D 2$

$---D 3$

(c)

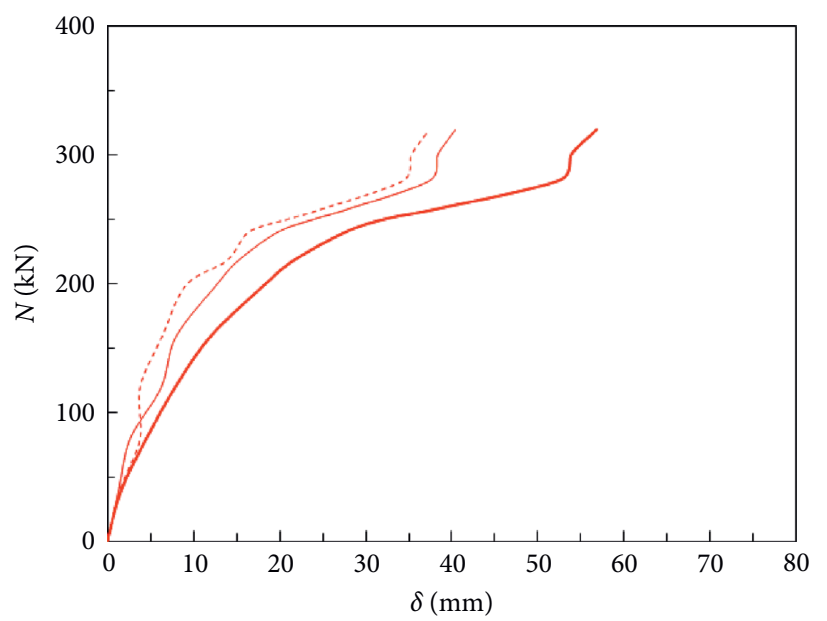

(d)

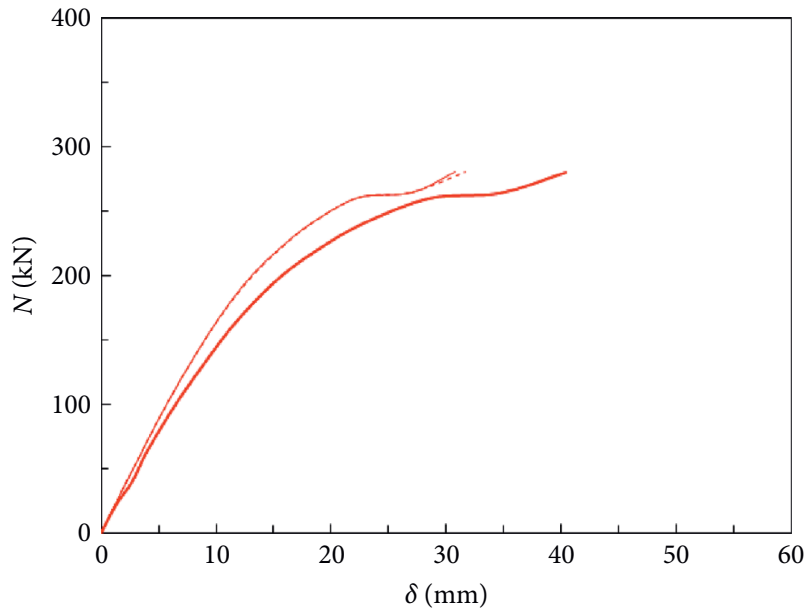

$D 1$
$-D 2$

$-D 1$

$-D 2$

- - D3

(e)

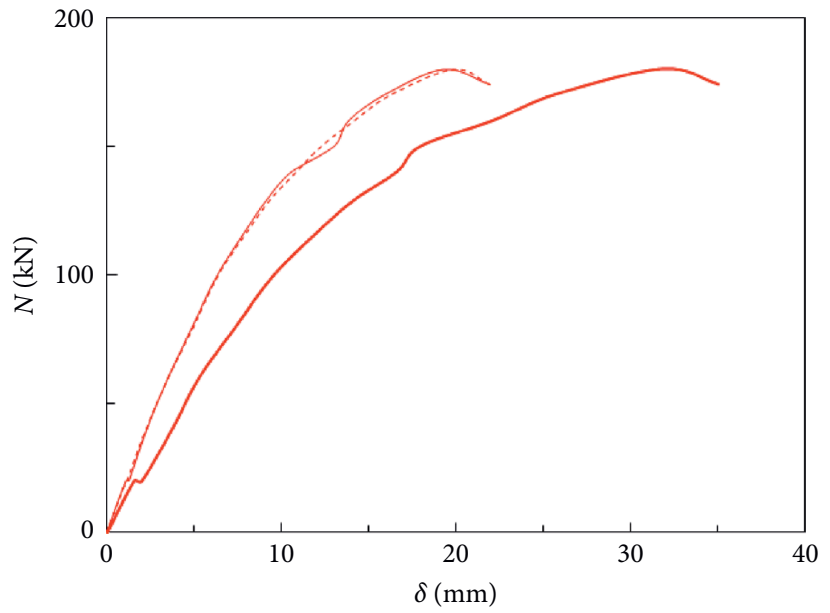

(f)

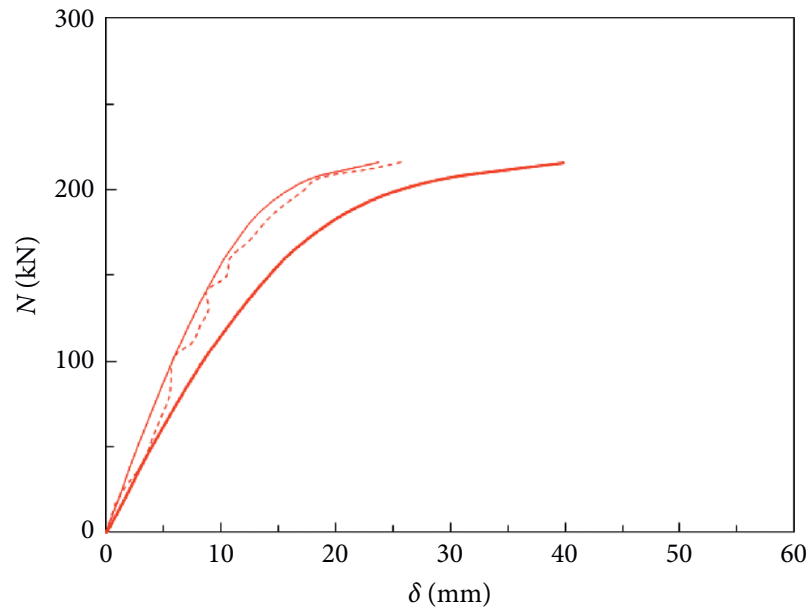

$-D 1$

- D1

$-D 2$

$-D 2$

- - D3

$--D 3$

(g)

(h)

Figure 9: Continued. 


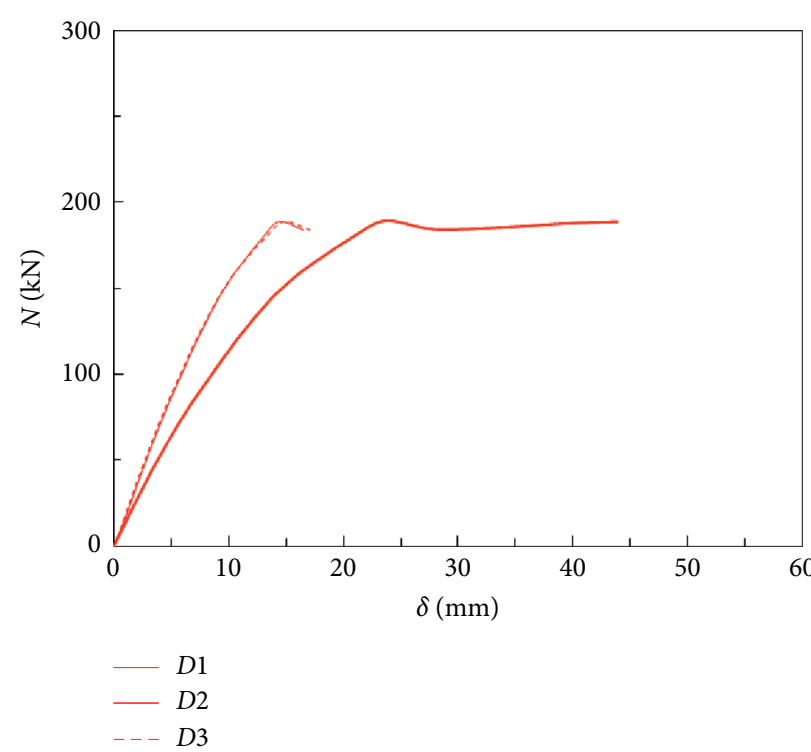

(i)

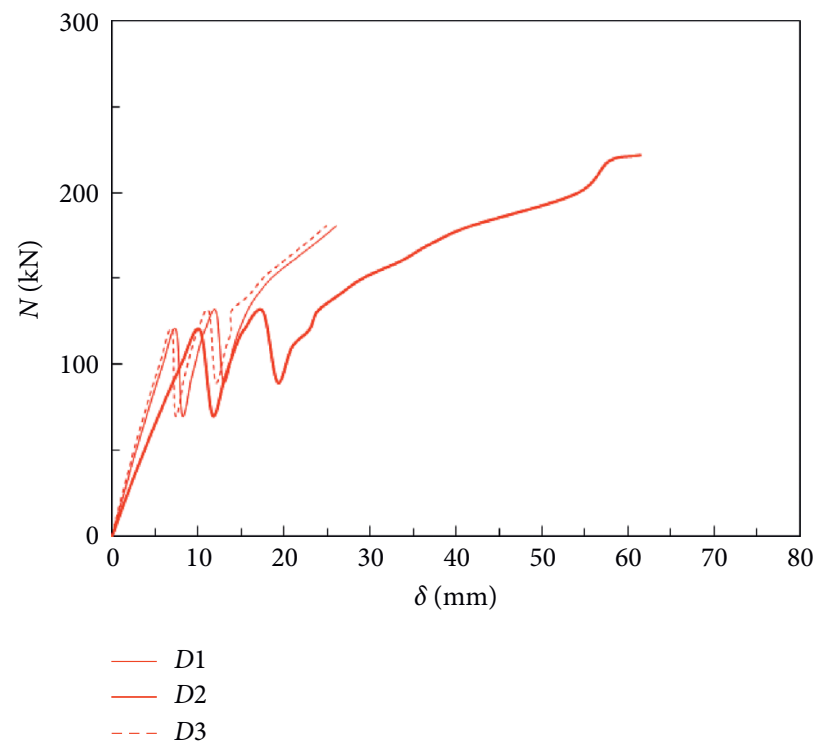

(k)

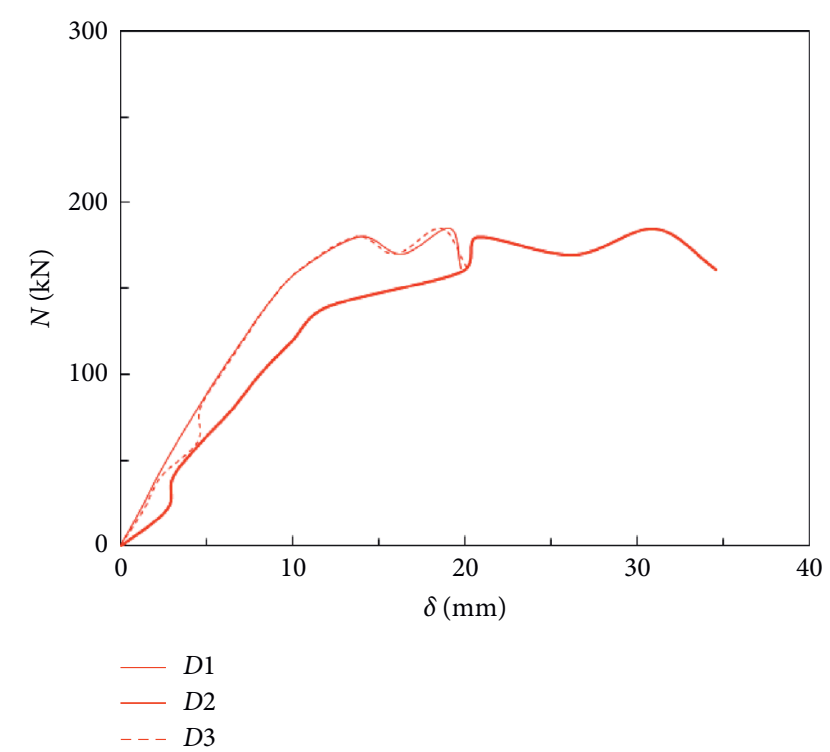

(j)

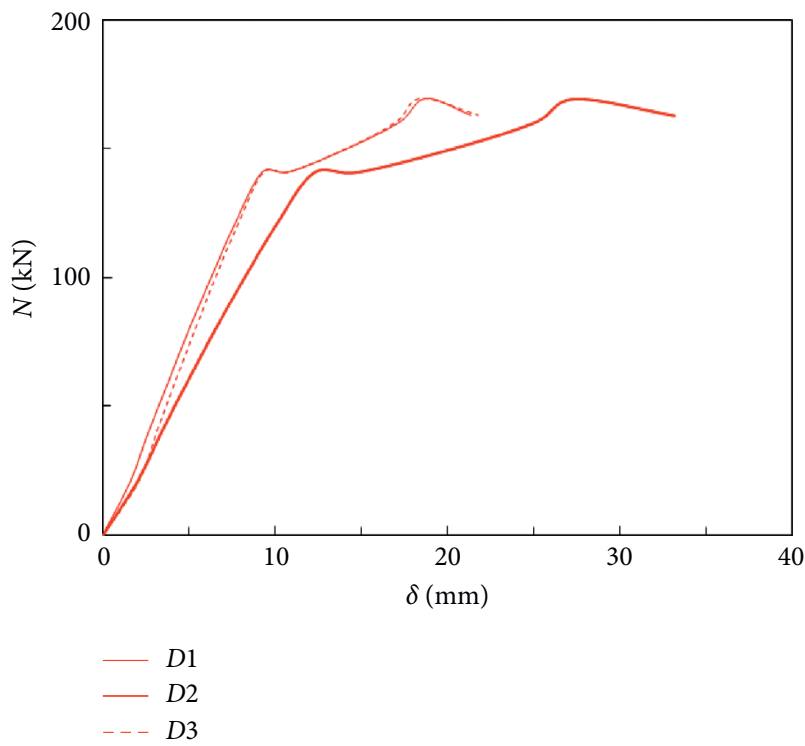

(1)

Figure 9: Load-vertical displacement curves. (a) PB-2. (b) FLB-1-S1. (c) FLB-1-S2. (d) FLB-2-F0. (e) FLB-2-F1. (f) FLB-2-F2. (g) EPB-1-N. (h) EPB-1-SW. (i) EPB-1-H. (j) CPB-1-N. (k) CPB-1-SW. (l) CPB-1-H

TABLE 3: Summary of key test results.

\begin{tabular}{lcccc}
\hline Specimens & $M_{\mathrm{y}}(\mathrm{kN})$ & $\Delta_{\mathrm{y}}(\mathrm{mm})$ & $M_{\mathrm{p}}(\mathrm{kN})$ & 144.0 \\
\hline PB-2 & 127.8 & 24.2 & 116.4 & $\Delta_{\mathrm{p}}(\mathrm{mm})$ \\
FLB-1-S1 & 102.1 & 17.6 & 108.9 & 30.3 \\
FLB-1-S2 & 93.1 & 14.4 & 140.0 & 35.5 \\
FLB-2-F0 & 126.0 & 18.9 & 159.5 & 23.1 \\
FLB-2-F1 & 123.9 & 33.4 & 140.0 & 56.9 \\
FLB-2-F2 & 121.5 & 23.6 & 135.0 & 40.4 \\
EPB-1-N & 116.7 & 20.3 & 162.0 & 31.9 \\
EPB-1-SW & 142.2 & 21.8 & 141.8 & 39.9 \\
EPB-1-H & 125.6 & 18.1 & 138.8 & 23.7 \\
CPB-1-N & 118.0 & 18.8 & 166.5 & 31.0 \\
CPB-1-SW & 132.8 & 40.0 & 127.1 & 61.4 \\
CPB-1-H & 108.8 & 17.3 & & 27.4 \\
\hline
\end{tabular}



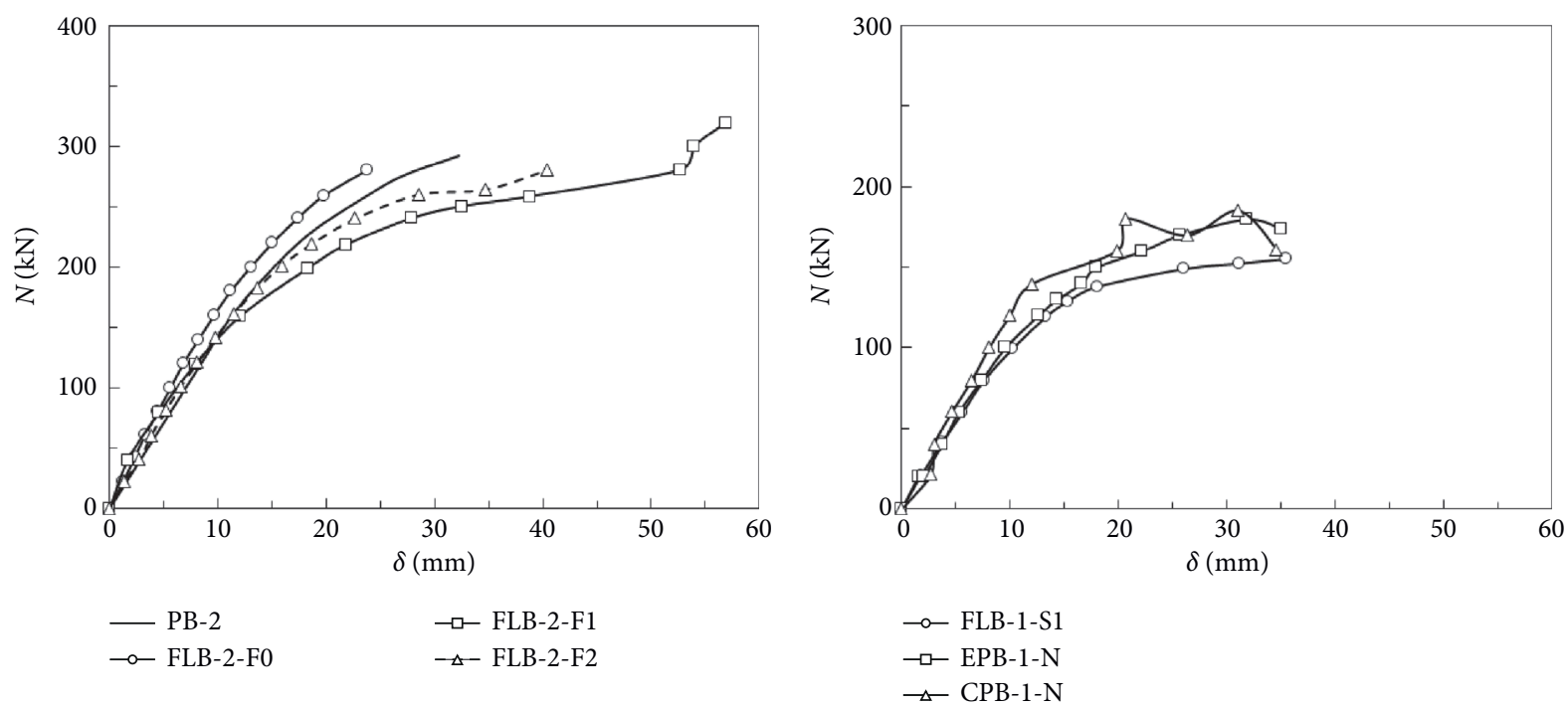

(a)
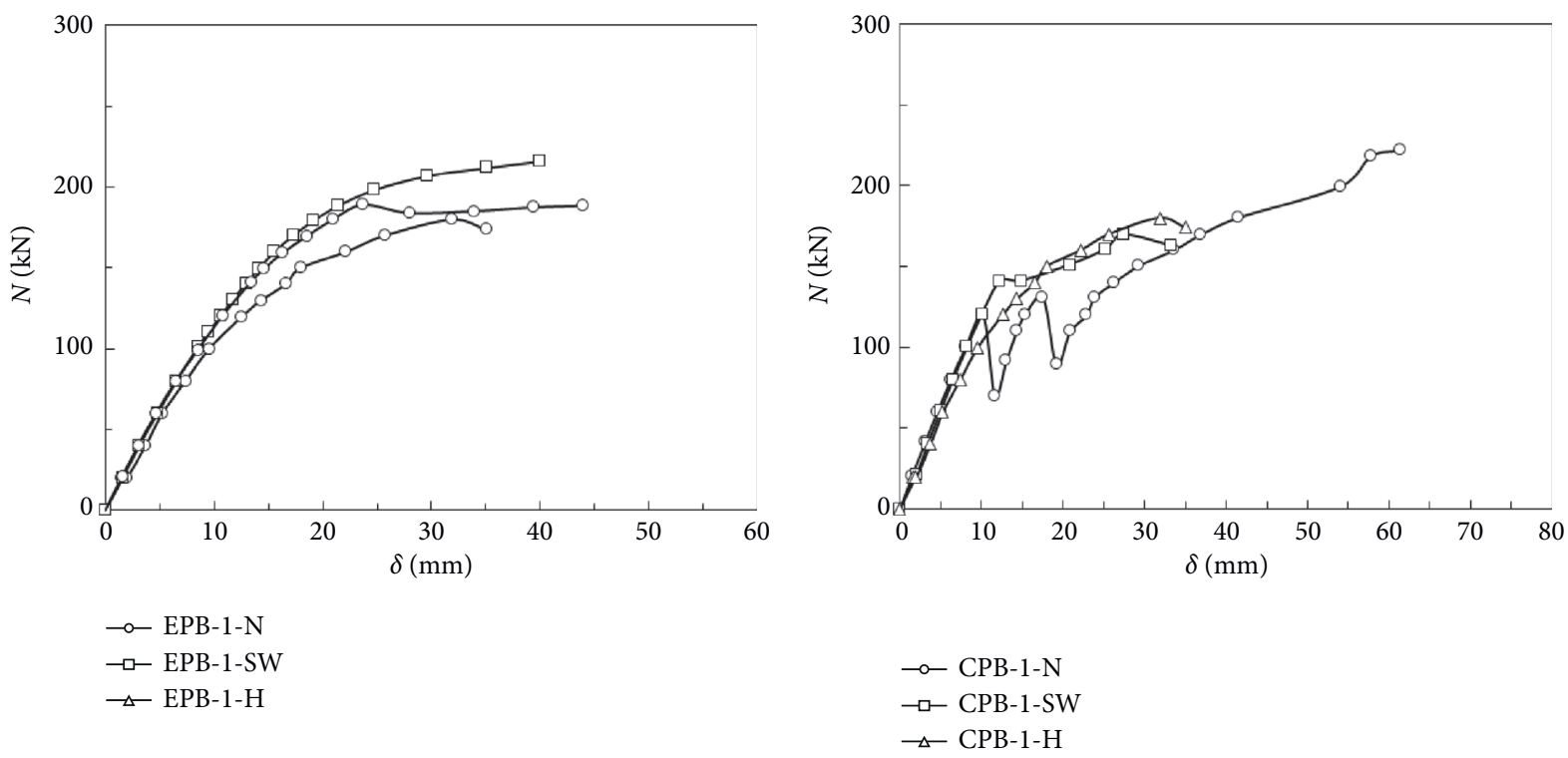

(c)

(d)

Figure 10: Influence of tested parameters on the load-vertical displacement curves. (a) EDB-spliced type (pure bending). (b) Spliced type (midspan loading). (c) Bolt types (EPB specimens). (d) Bolt types (CPB specimens).

the measured points of 5\# and 6\# displacement transducers (Figure 5(b)):

$$
\theta=\frac{\left(D_{5}-D_{6}\right)}{L_{r}} .
$$

The moment $(M)$ versus rotation angle $(\theta)$ curves for specimens under pure bending are shown in Figure 11. At the initial loading stage, $\theta$ increases linearly with the increasing $M$, followed by the rapid increase of rotation deformation beyond the yield load. For the FLB specimens, the thickness of filled plates has little influence on the initial stiffness despite the slight improvement observed in specimen FLB-2-F2. However, the deformability of specimens with filled plates is significantly improved. 


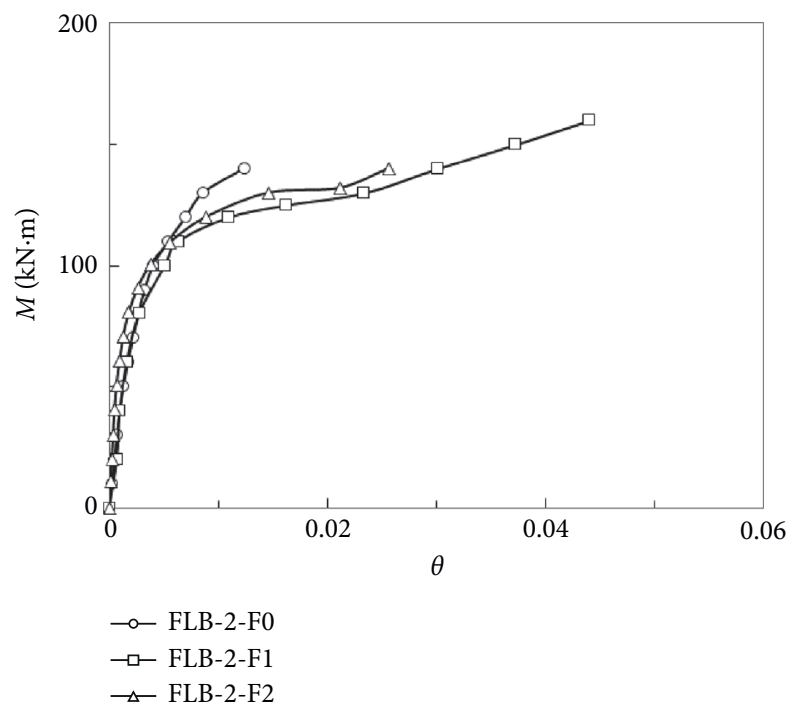

FIgURE 11: Moment-rotation angle curves for specimens under pure bending.

\section{Conclusions}

In this study, 12 specimens were tested to failure to investigate the performance of the bolt-spliced prefabricated steel frame beams. The investigated parameters include spliced types, loading patterns, and bolt types. Based on the experimental results, the following conclusions are summarized.

(1) For FLB specimens under pure bending, the opening of bottom flanges is observed during the loading process, which is restricted within the region fastened with bolts. A similar failure mode is found for FLB specimens subjected to midspan load. The displacements between the top flanges and bottom flanges of $\mathrm{CPB}$ specimens are found to decrease and increase, respectively. In addition, no obvious opening of flanges is found for EPB specimens.

(2) The vertical deformed shapes along the length of specimens under pure bending coincide better with the second-order parabolas and those for specimens subjected to midspan load are in better agreement with sinusoid curves.

(3) For specimens under pure bending, the use of filled plates will improve the deformability and reduce the initial stiffness. The strength of FLB specimens is close to that of the prototype beam. For specimens subjected to midspan load, the initial stiffness of FLB and EPB specimens is smaller than that of CPB specimens and the strength of EPB and CPB specimens is larger than that of FLB specimens.

(4) The initial stiffness of EPB specimens with normalstrength bolts with spring washer and high-strength bolts is nearly the same, which is larger than that of EPB specimens with normal-strength bolts. The strength of EPB specimens is improved due to the use of spring washer or high-strength bolt. In addition, a similar trend is found for CPB specimens with different types of bolts.

\section{Data Availability}

The data used to support the findings of this study are available from the corresponding author upon request.

\section{Conflicts of Interest}

The authors declare that they have no conflicts of interest.

\section{Acknowledgments}

The authors gratefully acknowledge the financial support provided by the National Natural Science Foundation of China (51778219), Hunan Natural Science Foundation (2018JJ2020, 2020JJ5018, and 2020JJ5020), and the Scientific Research Project of Education Department of Hunan Province (19A095 and 19B099).

\section{References}

[1] R. Sanches, O. Mercan, and B. Roberts, "Experimental investigations of vertical post-tensioned connection for modular steel structures," Engineering Structures, vol. 175, pp. 776-789, 2018.

[2] X. C. Liu, X. X. Zhan, S. H. Pu, A. L. Zhang, and L. Xu, "Seismic performance study on slipping bolted truss-to-column connections in modularized prefabricated steel structures," Engineering Structures, vol. 163, pp. 241-254, 2018.

[3] Z. Q. Jiang, X. F. Yang, C. Dou, Y. L. Pi, and R. Li, "Design theory of earthquake-resilient prefabricated beam-column steel joint with double flange cover plates," Engineering Structures, vol. 209, Article ID 110005, 2019.

[4] X. Chen and G. Shi, "Cyclic tests on high strength steel flangeplate beam-to-column joints," Engineering Structures, vol. 186, pp. 564-581, 2019.

[5] A. Basta, M. H. Serror, and M. Marzouk, "A BIM-based framework for quantitative assessment of steel structure 
deconstructability," Automation in Construction, vol. 111, Article ID 103064, 2020.

[6] G. L. Kulak and D. L. Green, "Design of connectors in webflange beam or girder splicers," Engineering Journal, vol. 27, no. 2, pp. 41-48, 1990.

[7] K. M. McMullin and A. Astaneh-Asl, "Steel semirigid columntree moment resisting frame seismic behavior," Journal of Structural Engineering, vol. 129, no. 9, pp. 1243-1249, 2003.

[8] M. A. Q. Al-Janabi, "Static and dynamic behavior of spliced steel girders," Ph. D. Thesis, University of Baghdad, Baghdad, Iraq, 2011.

[9] Q. C. Li, G. Liu, A. J. Hu, and D. H. Zhu, "Experimental study on frictional energy-dissipation behavior of bolted steel beam splicing in rigid frame," Building Structures, vol. 41, no. 5, pp. 78-81, 2011, in Chinese.

[10] E. A. Sumner, "Unified design of extended end-plate moment connections subjected to cyclic loading," Ph. D. Thesis, Virginia Polytechnic Institute and State University, Blacksburg, Virginia, 2003.

[11] A. K. Dessouki, A. H. Youssef, and M. M. Ibrahim, "Behavior of I-beam bolted extended end-plate moment connections," Ain Shams Engineering Journal, vol. 4, no. 4, pp. 685-699, 2013.

[12] P. Kawecki and A. Kozlowski, "Experimental investigation of end-plate splices with multiple bolt rows of large girders," Journal of Constructional Steel Research, vol. 167, Article ID 105859, 2019.

[13] L. W. Tong, X. L. Mou, F. Zhou et al., "Flexural behavior of bolt-spliced steel beams," Journal of Tongji University (Natural Science), vol. 46, no. 9, pp. 1175-1181, 2018, in Chinese.

[14] GB/T 228-2010, Metallic Materials-Tensile Testing-Part1: Method of Test at Room Temperature, China Standard Press, Beijing, China, 2010, in Chinese. 